
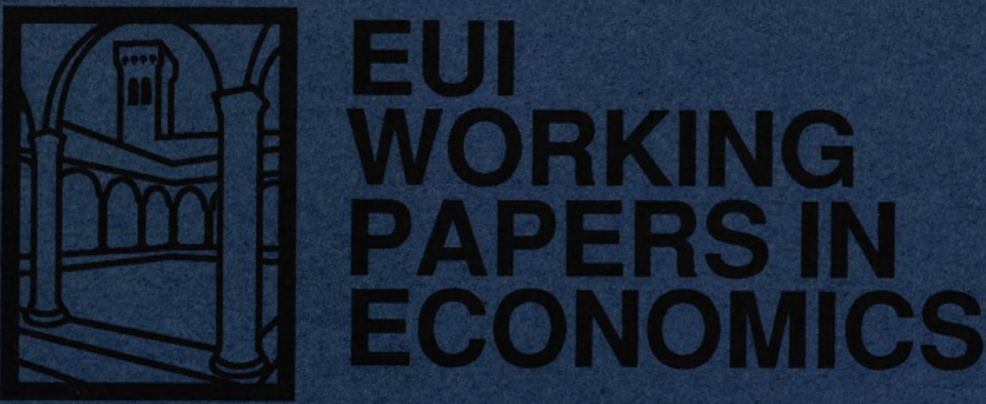

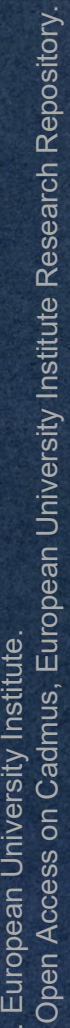

EUI Working Paper ECO No. $92 / 1$

Long-Run Consequences of

Finite Exchange Rate Bubbles

\title{
Aliessandra PELLONI
}




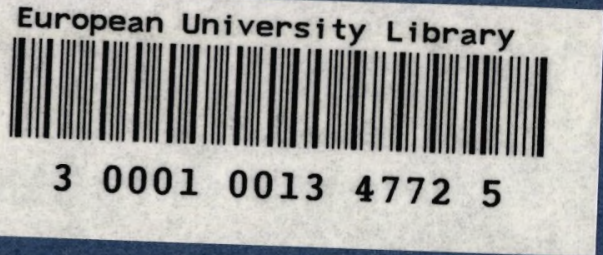

\section{Please note}

As from January 1990 the EUI Working Paper Series is divided into six sub-series, each sub-series is numbered individually (e.g. EUI Working Paper LAW No. 90/1).

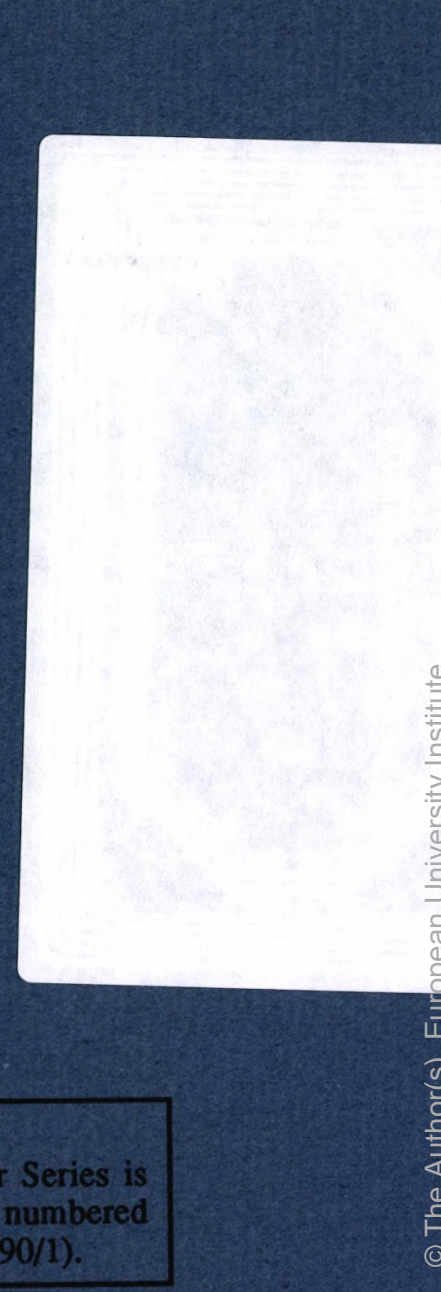


EUROPEAN UNIVERSITY INSTITUTE, FLORENCE ECONOMICS DEPARTMENT

EUI Working Paper ECO No. 92/71

Long-Run Consequences of Finite Exchange Rate Bubbles

ALESSANDRA PEULONI

BADIA FIESOLANA, SAN DOMENICO (FI) 
All rights reserved.

No part of this paper may be reproduced in any form without permission of the author.

(C) Alessandra Pelloni

Printed in Italy in April 1992

European University Institute

Badia Fiesolana

I-50016 San Domenico (FI)

Italy 
LONG-RUN CONSEQUENCES OF FINITE EXCHANGE RATE BUBBLES.

by

Alessandra Pelloni

European University Institute

April 1992

Abstract

This paper draws on the literature on exchange rate instability and on sunk-cost hysteresis to analyse the long-run effects of temporary exchange rate shocks. We propose two versions of the Dornbusch (1976) monetary model, modified so as to allow for endogenous adjustment in productive capacity, with the aggregate investment function being linear with respect to the exchange rate in one version and non-linear in the other. For both versions, we provide solutions for a Blanchard-type bubble (exogenously) developing on the foreign exhange market. We find that, if capacity adjusts nonlinearly, such a bubble will affect the steady-state of the economy.

I wish to thank Marcello De Cecco, Mark Salmon and Robert Waldmann for their help and supervision at the European University Institute. 


\section{Introduction}

It has been recognized for some time, in particular in connection with exchange rate theory, that irrelevant events such as "sunspots" may shape actual economic outcomes, through expectational influences (see, for instance, Dornbusch 1982). The apparent excess volatility of exchange rates and events in equity markets have stimulated renewed interest in increasing our understanding of such phenomena and in determining the circumstances in which deviations from the level dictated by fundamentals are consistent with full rationality. ${ }^{1}$ The current state of the debate indicates that we cannot rule out the existence of rational bubbles on purely theoretical grounds, ${ }^{2}$ and reinforces the need to investigate their importance empirically.

In a deterministic bubble, expectations about the future asset prices are always fulfilled but the bubble process is not stationary, even when "fundamentals" are. Blanchard (1979) has developed an example of a non stationary bubble that has a constant (exogenously given) probability of bursting. This means that such bubbles will not go on forever, as is necessary for implausible "deterministic" bubbles to be rational.

In the original formulation of bubbles with a finite life, the effect of asset prices on fundamentals was not modelled although Blanchard and Watson (1982) admit its importance. An advance in the direction of such modelling is made by Miller and Weller (1989) who analyse the macroeconomic impact of foreign exchange market bubbles. However, in their paper, only temporary effects on the course of "fundamentals" are considered: the bubble is assumed to be neutral in 
the long run.

More recently, the possibility of an influence of temporary exchange rate shocks on the underlying structure of the economy has been brought to the foreground by a burgeoning literature on hysteretic effects in trade and labour markets. Such a possibility means, as regards the fixed versus flexible exchange rates debate, that the choice will affect the first and not only the second moments of the real variables.

Some consequences of one kind of hysteresis, the so called sunk-cost hysteresis, for international trade have been explored in the literature. The seminal papers by Baldwin (1986) and Dixit (1987) propose models of hysteretic behaviour by traded goods producers and suggest that large exchange shocks may shift historical relationships between exchange rate and trade flows, leading firms to make entry or exit decisions in foreign markets which are not reversed when the currency returns to its previous level.

A first attempt to go beyond a partial equilibrium approach and to model the feed-back from hysteresis in trade to the exchange rate is in Baldwin and Krugman (1989). To do this, they go back to the "elasticity approach" of exchange rate determination. ${ }^{3}$ A step forward in the analysis is made by Baldwin and Lyons (1989) who implement the Dornbusch (1976) model. They consider the macro implications of the presence of micro-level sunk-cost hysteresis in the long run for the autonomous component of aggregate demand for domestic products.

However it seems at least as important to take into account the possibility of hysteretic effects of large exchange rate movements on aggregate supply, which through the investment and entry and exit 
decisions of domestic firms, will be seen to depend on past as well as current aggregate demand disturbances.

In this paper we analyse the development of a Blanchard type exchange rate bubble ${ }^{4}$ using again the Dornbusch model, modified so as to allow for capacity being a function of the history of the real exchange rate. The question we ask is whether the corrective shock represented by the bursting of the bubble is always sufficient to allow the economy to go back to the path followed before the inception of the bubble. The answer turns out to depend upon the specific form that the reaction of long run supply to demand conditions assumes, i.e. on the specific form of hysteresis in the "natural" level of income.

We investigate two different cases: in the first one sunk-cost hysteresis leads to non linearities in the aggregate investment function with respect to the exchange rate so that the natural level of income changes discretely when the real exchange rate hits some trigger values.

To characterize the solution in this first model we build on the technique used by Wilson (1979) to analyse anticipated shocks in dynamic rational expectations models. The procedure we devise allows one to analyse all situations in which what is known is not the time at which the shock will happen, but the fact that the shock will happen when some endogenous variable hits some trigger level. We find that a temporary nominal disturbance such as a bubble is sufficient to affect permanently the economy, leading to steady-state changes in real income and real exchange rate. This implies that PPP need not hold even in the long run. 
In the second model we propose, the reaction of aggregate supply to demand shocks takes place in continuous fashion, as aggregation smooths microlevel discontinuities. The system we obtain is hysteretic in the sense that its transition matrix is singular, so that long-run values of the endogenous variables depend on initial conditions. We show how, by a mathematical "sleight of hand", it is possible to obtain a solution to the model without going through the heavy calculations required by the formula provided in Giavazzi and Wyplosz (1980) to deal with the "zero root problem". By solving this second model we find that temporary exchange rate disturbances such as bubbles are not sufficient to alter the economic outcomes in the long run, so that an exchange rate bubble will provoke only a temporary welfare loss. However we show it is important for policy that the hysteretic forces at work are recognized so that this loss which need not be negligible, can be avoided.

The paper is organized as follows: in the next section we briefly discuss sunk-cost hysteresis and its implications for aggregate supply changes, in the third we derive the solution for a stochastic exchange rate bubble when the non inflationary level of income jumps to a new level if the real exchange rate hits some trigger points; in the fourth section we consider the alternative continuous formulation of path dependence in the non inflationary level of income. The last section draws conclusions and indicates some possible extensions to the analysis. 


\section{Sunk-cost Hysteresis}

Hysteresis appears in models in which the stationary equilibrium depends on initial conditions so that temporary shocks have effects that do not go away when the shocks themselves cease to be. This can occur in any dynamic system which has multiple steady state equilibria so that a shock may move the system from one steady state equilibrium to another. Hysteresis can arise in different models for totally different economic reasons. In international economics particular attention has been given to sunk-costs as a possible source of hysteresis. ${ }^{5}$ The logic of sunk-cost hysteresis is simple: if to enter a market a fixed unrecoverable cost must be payed, to stay in a market is cheaper for an established firm than for entrant. Therefore demand conditions (i.e. a real exchange rate level) which are sufficiently good for the former to stay active will not induce to action the latter, i.e. the level of the exchange rate inducing entry will be different from the level inducing exit. Between the two levels is a "hysteresis band".

So far we are still in the Marshallian theory of the long versus the short run, based on the gap between the full and the variable cost. The current generation of models adds to that theory an explicit treatment of the expectations which firms, operating in different market structure, ${ }^{6}$ form about their forcing variables i.e., for firms engaged in international trade, the real exchange rate. The possibility of sunk-cost hysteresis has been shown for a broad class of assumptions concerning the firms' beliefs about the process governing the real exchange rate. Dixit (1987), (1989) and (1990) 
adopts a continuous time setting, the forcing variable follows a brownian motion process, for which it is possible, using Bellman's optimality principle and exploiting the analogy with option pricing, to find closed-form solutions. He shows that uncertainty dramatically widens the hysteresis band, for a given level of sunk-costs and variable costs, encouraging an attitude of wait-and-see by firms. Dixit suggests that the presence of mean reversion in the process governing the forcing variable will further widen the inaction zone. Other authors use a discrete time setting: in Baldwin and Krugman (1989) the variable is white noise, in Baldwin and Lyons (1989) it is an AR(1), and in Baldwin (1989) a general ARMA process; in all these cases the solution to the problem is obtained by using dynamic programming tecniques, which do not yield explicit calculations for the threshold values but are sufficient to prove the existence and boundedness of the band and to characterize how the width and position of the band are affected by changes in the size of sunk-costs and in the degree of uncertainty and persistence of the forcing variable process. In particular, Baldwin (1989) proves that the band-widening effect of volatility does not hold in general ${ }^{7}$ but holds for processes sufficiently close to a random walk.

These articles show that shocks perceived by firms as temporary may lead to abandonment of sunk assets i.e. to hysteretic changes in the economic structure. To consider the simplest case of temporary shocks, suppose the maximum level of profits a firm can earn at any point in time, $\pi$, is an increasing function of the real exchange rate $v$, which is driven by a white noise process. The fixed entry cost is F. Let $V_{1}\left(V_{0}\right)$ be the expected present value to the firm of being in 
(out of) the market. By the Bellman optimality principle the firm will enter if $v \geq v_{i}$ where $v_{1}$ is such that $\pi\left(v_{1}\right)=F+\delta\left(v_{0}-v_{i}\right)$ and $\delta$ is the time discount factor and will exit if $v \leq v_{0}$ where $\pi\left(v_{0}\right)=$ $\delta\left(v_{0}-v_{i}\right)$. It is clear that $v_{i}>v_{0}$. Thus a sufficiently large deterioration in profitability e.g. due to an overvaluation of the real exchange rate, may lead to profits falling below the critical level $\pi_{0}=\pi\left(v_{0}\right)$ and the firm leaving the market. However it will only re-enter if the real exchange rate depreciates enough as to make profits exceed the level $\pi_{i}=\pi\left(v_{i}\right)$. If the exchange rate was originally in the range $v_{0}<v<v_{1}$, a temporary overvaluation will have a permanent effect, so that a large temporary undervaluation may be necessary to restore the initial situation.

The specific kind of sunk-costs on which models of trade hysteresis have focussed are the costs necessary for exporting firms to set up a distribution net, to adapt the product to foreign tastes and regulations etc., assets that firms give up when they leave the foreign market. When this happens the autonomous component of demand for domestic exports is lowered. However a much larger class of investment costs are "sunk": ${ }^{8}$ once installed, capital has little value unless used in production. Markets for used facilities are thin and discount them heavily, partly for "market of lemons" reasons. This means that the adjustment of productive as well as of commercial capacity at the micro level will be discontinuous, so that if a recession has led to the scrapping of machines, ${ }^{9}$ closing down of plants and exit of firms, it will not be sufficient for demand to get to the previous level for potential output to go back to its previous path. The same level of demand will then be consistent with a range 
of capacities depending on past history. A complete macroeconomic analysis of an episode of excessive appreciation will have to take this adverse effect on capacity into account.

However, to do so, one has previously to deal with the problem of aggregation of micro-level reactions. In fact, hysteresis has been shown to arise from sunk-costs in partial equilibrium settings. The simple general equilibrium analysis in Baldwin and Lyons (1989) implicitly assumes that statements valid at the single industry level will apply to the whole economy. The problem of aggregation through the economy is given some attention in Baldwin and Krugman (1986). They argue that, even if there is a continuous distribution of firms in terms of the real exchange rates that will make them invest or disinvest, it is not the case that there is always a firm on the margin of entry or exit, so that hysteresis bands will not be always eliminated at the aggregate level. Their reasoning however is not explicitly extended to the case in which there is a continuous distribution of firms in terms of the levels of their sunk-costs. Bean (1990), focussing on the British case, concludes that the data do not permit either to confirm or disprove that the relationship between aggregate investment and the aggregate rate of profit is linear. On the whole it seems impossible to get a clearcut theoretical answer on the point; further empirical investigation is obviously needed.

In this paper we consider two extreme cases, one in which the trigger features of partial equilibrium models are inherited at the macro level and the other in which they are smoothed away. One could think of adjustment in capacity as being smooth over a range of 
values of the real exchandge rates and exhibiting a discrete trigger feature for other values. By combining the tecniques we use for the two extreme cases, it would then be possible to analyse more complex, intermediate cases.

\section{Exchange Rate Bubbles and Discrete Capacity Adjustment.}

We characterize below the solution for a rational bubble, in a sticky price monetary model where adjustment in capacity takes place non linearly in response to demand shocks.

The equations of the model, before the starting of the bubble are as follows:

$$
\begin{aligned}
& m-p=k y-l i \\
& y=b\left(e-p+p^{*}\right) \\
& D p=c\left(y-y_{n}\right) \quad \text { or } \quad p=c \int_{-\infty}^{t}\left(y(s)-y_{n}(s)\right) d s \\
& D e=i \quad i^{*} \quad \text { or } \quad e=\int_{-\infty}^{t}\left(i(s)-i^{*}(s)\right) d s
\end{aligned}
$$

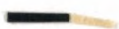

where the symbols used are defined as follows:

$$
\begin{aligned}
& m=\text { the } \log \text { of the domestic money stock } \\
& p=\text { the log of the price of domestic final product }
\end{aligned}
$$


$y=$ the $\log$ of the GNP

$y_{n}=$ the $\log$ of the non inflationary level of GNP

$\mathrm{e}=$ the $\log$ of the exchange rate, defined as the domestic currency price of the foreign currency

$i=$ the (instantaneous) domestic nominal interest rate

* denotes a variable in the rest of the world

A bar above a variable denotes its long run value.

Equations (1) and (2) are the LM and IS curves respectively, (3) is a simple unaugmented Phillips curve and (4) an uncovered interest parity equation, which follows from individual optimization if agents are risk-neutral and the inflation rate is known with certainty, as is the case in this model, where it depends only on currently observed variables (prices, nominal exchange rates and the non inflationary level of income).

We have that when large shocks take the real exchange rate past a trigger level, potential output changes discretely. The assumed relationship between $y_{n}$ and the real exchange rate is illustrated in Fig. 1.Starting at the origin where $y_{n}$ equals $y_{n 0}$, it remains at this level provided $v$, the real exchange rate, remains between $\bar{v}_{0}$ and $\underline{v}_{0}$. But if, for example, $v$ falls below $\underline{v}_{0}$ then $y_{n}$ falls to $y_{n 1}$ as firms in the domestic economy reduce capacity. Since there is a new set of "marginal" firms (firms which are on the point of investing or disinvesting, there are new trigger points $\bar{v}_{1}$ and $\underline{v}_{1}$, which are lower than the old ones. If the real exchange rate continues to fall and passes $\underline{v}_{1}$, then $y_{n}$ falls again to $y_{n 2}$. Moreover, $y_{n}$ does not return to $y_{n o}$ until the real exchange rate crosses the upper 
bound point $\overline{\mathrm{v}}_{1} \cdot 10$

The equations of the model can be represented as:

$$
\left[\begin{array}{c}
\mathrm{De} \\
\mathrm{Dp}
\end{array}\right]=\left[\begin{array}{ccc}
\mathrm{kbl} & -1 & (1-\mathrm{kb}) \mathrm{l}^{-1} \\
\mathrm{cb} & -\mathrm{cb}
\end{array}\right]\left[\begin{array}{l}
\mathrm{e} \\
\mathrm{p}
\end{array}\right]+\left[\begin{array}{c}
-\mathrm{ml}^{-1}-\mathrm{i}^{*} \\
-\mathrm{cy}
\end{array}\right]
$$

The determinant of the transition matrix is negative, indicating a saddle point equilibrium. There is a unique stable solution of the following form:

$$
e-\bar{e}=(c b+z) c^{-1} b^{-1}(p-\bar{p})
$$

where $z_{1}$ is the negative eigenvalue. We notice that the saddle path is positively sloped if $\mathrm{kb}>1$, horizontal if $\mathrm{kb}=1$ and negatively sloped otherwise. All other integral curves constitute divergent paths and correspond economically to the notion of deterministic self-fulfilling speculative bubbles. These bubbles however must never burst if they are to satisfy the postulate of rationality, causing the system to diverge more and more from equilibrium as time passes . For any given value of $y_{n}$, the solution of the system is of the kind seen above. However when the real exchange rate crosses a bound of a no exit- no entry band, the long-run equilibrium changes and there is an identical set of paths passing through the new equilibrium. In fact there is a whole chain of equilibrium points, each with its associated set of solutions. In order to introduce in this model a stochastic bubble of the kind proposed by Blanchard, we modify the arbitrage equation (4). Let us assume that the bubble 
has a costant probability of bursting, $n$, in the unit of time; this probability is assumed for simplicity to be exogenously given, even if it could, inter alia, well depend in reality on the duration of the bubble itself. In models which do not consider the impact of a bubble on fundamentals, the bursting of a bubble consists in an immediate return of the asset price to its long run equilibrium level; however in the presence of a predetermined variable, here the price level, the most appropriate way to characterize the behaviour of the asset price when the bubble bursts is to assume that it collapses to the saddle path, along which it moves until reaching the long run position. In discrete time the arbitrage equation becomes:

$$
(1-n)\left(e_{t+1}-e_{t}\right)+n\left(\left(c b+z_{1}\right) c^{-1} b^{-1}\left(p_{t+1}-\bar{p}\right)+\bar{e}-e_{t}\right)=i_{t}-i_{t}^{*}
$$

On the right-hand side we have the interest differential, on the left-hand side the expected rate of change in the exchange rate. This is a weighted average of the change which must occur if the bubble persists and the magnitude of the collapse if the bubble bursts, each multiplied by its probability. We notice that the coefficient linking the deviations from long run values of the price level and the exchange rate along the stable manifold is the same in continuous and in discrete time and also that the expressions of long run values are the same. It is then possible, proceeding to the limit in which the time interval becomes arbitrarily small, to go to: 


$$
D e-n\left(e-\bar{e}-(c b+z) c^{-1} b^{-1}(p-\bar{p})\right)=i-i^{*}
$$

For ease of exposition we take $y_{n}$ as given for the moment, ignoring hysteresis, so that the stationary equilibrium of the system with bubble and of the system without bubble are the same. We have:

$$
\left[\begin{array}{c}
D e \\
D p
\end{array}\right]=\left[\begin{array}{cc}
n+k b l^{-1} & -n(c b)^{-1}\left(c b+z_{1}\right)+(1-k b) 1^{-1} \\
b & -c b
\end{array}\right]\left[\begin{array}{c}
e-\bar{e} \\
p-\bar{p}
\end{array}\right]
$$

The eigenvalues of this system are:

$$
z^{\prime}=\left[n+k b l^{-1} c b \pm\left((n+k b / l-c b)^{2}+4\left(c b l^{-1} n z\right)\right)^{1 / 2}\right] / 2
$$

One is positive and the other is negative, so we have again a saddle point configuration. In particular it is easily shown by substituting that the negative root is equal to $z_{1}$, so that the saddle path is equal to that of the previous system, while the unstable root and hence all other trajectories are affected by the bubble; in particular, the new linear unstable path is steeper than in the bubbleless system (6). This is shown in Fig. 2 were the solid lines represent the bubbleless system and the dotted 1 ines the system after the inception of a bubble. More specifically we notice that along the unstable paths of the latter the exchange rate diverges from equilibrium more rapidly than along the unstable paths of the former, since now the expected rate of change of thee exchange rate must compensate not only for the interest differential but also for the probability of a crash. 
We can now relax the assumption that capacity is given and consider that sizable changes in demand will affect it. Suppose we start at an equilibrium characterized by $y_{n}=y_{n 1}$. If a finite bubble develops, the system will have a solution of the kind:

$$
\begin{aligned}
& e_{1}=B_{1} \exp z_{1} t+B_{2} \operatorname{expz} z_{2}^{\prime}+\bar{e}_{1} \\
& p_{1}=a_{1} B_{1} \operatorname{expz} z_{1} t+a_{2}^{\prime} B_{2} \operatorname{expz} z_{2}^{\prime} t+\bar{p}_{1}
\end{aligned}
$$

where $a_{2}^{\prime}=c b\left(c b+z_{2}^{\prime}\right)^{-1}$

The subscript on the variables refers to the fact that $y$ is not a parameter: for instance $\overline{\mathrm{e}}_{1}$ is the steady-state nominal exchange rate conditional on the non inflationary level of income $y_{n 1}$.

Two alternatives are possible: one is that $\mathrm{e}_{1}(0) \neq \overline{\mathrm{e}}_{1}$, so that a bubble starts, but that $\underline{v}_{1} \leq e_{1}(0)-\bar{p}_{1} \leq \bar{v}_{1}$ the second is that $\mathrm{e}_{1}(0)-\overline{\mathrm{p}}_{1} \leq \underline{\mathrm{v}}_{1} \quad$ (to illustrate the model, from now on we will consider cases in which the lower bound $\underline{v}_{1}$ is reached) so that the misalignment is large enough to induce scrapping of sunk-assets and we move to another system centered at $y_{n}=y_{n 2}$. After the inception of a bubble, to calculate the time $T$ when the lower bound will be reached, given $e_{1}(0)$ (which along with $p_{1}(0)=\bar{p}_{1} \operatorname{determines} B_{1}$ and $B_{2}$ ) we must solve the equation:

$$
\begin{aligned}
e_{1}(T)-p_{1}(T) & =B_{1}\left(1-c b\left(c b+z_{1}\right)^{-1}\right) \exp z_{1} T \\
& +B_{2}\left(1-c b\left(c b+z_{2}^{\prime}\right)^{-1}\right) \exp z_{2}^{\prime} T+\bar{e}_{1}-\bar{p}_{1}=\underline{v}_{1}
\end{aligned}
$$


However this equation has no analytical solution and, of course, it is possible that it has no solution; in this latter case the upper bound is reached by the bubble so that this other equation has a solution:

$$
\begin{aligned}
e_{1}\left(T^{\prime}\right)-p_{1}\left(T^{\prime}\right) & =B_{1}\left(1-c b\left(c b+z_{1}\right)^{-1}\right) \operatorname{expz} T_{1} \\
& +B_{2}\left(1-c b\left(c b+z_{2}^{\prime}\right)^{-1}\right) \operatorname{expz} T_{2}^{\prime}+\bar{e}_{1}-\bar{p}_{1}=\underline{v}_{1} \text { (14) }
\end{aligned}
$$

However we will just examine the first case : the second one can be analysed along the same lines. What is not possible is that neither (13) nor (14) have a solution. In fact all trajectories, except the saddle path, asymptotically converge to the linear unstable path. Given that the slope of the unstable path is more than 45 degrees this path will intersect any 45 degrees line: now the profitability contours of firms, outside which we have industrial reallocation are just 45 degrees lines. So all trajectories will intersect them. A possibility we have already noticed is that $T=0$, i.e. the initial exchange rate is such that the long run equilibrium is immediately affected. Once we know T, it is easy to calculate the behavior of the bubble from there on. We have:

$$
\begin{aligned}
e_{2}(t) & =c_{1} \operatorname{expz}_{1} t+c_{2} \operatorname{expz}_{2}^{\prime} t+\bar{e}_{2} \\
p_{2}(t) & =c_{1}\left(1-\operatorname{cb}\left(c b+z_{1}\right)^{-1}\right) \operatorname{expz}{ }_{1} t+ \\
& +c_{1}\left(1-\operatorname{cb}\left(c b+z_{2}^{\prime}\right)^{-1} \operatorname{expz} z_{2}^{\prime}+\bar{p}_{2}\right.
\end{aligned}
$$

$C_{1}$ and $C_{2}$ are calculated by the conditions: 


$$
\begin{aligned}
& e_{2}(0)=e_{1}(T) \\
& p_{2}(0)=p_{1}(T)
\end{aligned}
$$

Equation (17) is an arbitrage condition, equation (18) derives from $p$ being a predetermined variable. Since $\bar{v}_{2}>\underline{v}_{1}>\underline{v}_{2}$, that means that at $T$ (with reference to the old system) or at 0 (with reference to the new system), equilibrium is centered around $y_{n 2}$.

Even if it is not possible to get a closed-form solution for T, we can provide a qualitative characterization of the features of the evolution of the bubbles. We have that $d \bar{p}=-k d \bar{y}$ and that $\mathrm{de}=(1-b k) b^{-1} d \bar{y}$. As regards the change in the vertical intercept of the saddle path $I_{s}$, we have $d_{s}=\left(b^{-1}+z_{1} k c^{-1} b^{-1}\right) d \bar{y}$ and some algebra shows that the expression inside the parentheses is negative iff bk $>1$. The change in the vertical intercept of the linear unstable path $I_{u}$ is $d_{u}=\left(b^{-1}+z_{2} k^{-1} c^{-1}\right) d \bar{y}$ where the expression inside the parentheses is positive.

In Fig. 3 and Fig. 4 the cases in which $\mathrm{kb}<1$ and $\mathrm{kb}=1$ are illustrated respectively. In both figures, before the beginning of the bubble, the economy is at point 1 , in a long run equilibrium position, with $y_{n}=y_{n 1}$. Then the bubble starts, due for instance to some extraneous information reaching the foreign exchange market, and the nominal exchange rate jumps to point $A$. The solution of the system corresponding to that point is then followed until point B (of course assuming the bubble does not collapse before that point is attained). At $B$ we have a reduction of productive capacity, so that 
the system relative to $y_{n}=y_{n 2}$ becomes relevant, finally at $C$ we assume the bubble bursts, which means that the exchange rate jumps to point $D$, on the new saddle path, then sliding towards the new long run equilibrium at 2 .

In both the cases shown unless the bubble bursts before the critical point is reached, the final outcome is hysteresis of potential output. However this is not the only possible result : another potential outcome is that, when the bubble bursts, the devaluation of the exchange rate is such as to cross the upper border of the system centred at 2 , so that the new long run equilibrium will be centred at 1 again. This possibility is shown again in Fig 4: if the bubble, after having reached point $B$ bursts at point $C^{\prime}$, the devaluation will move the system to point $D^{\prime}$, which is above the upper bound of the system centred at 2 . This means that we are back to the system centred at 1 . However, if that is the case we would have to reformulate the model in the sense that, starting from the point when the bursting of the bubble would be incompatible with the given level of yn the1 arbitrage equation would become:

$$
D e-n\left(e-\bar{e}_{1}-\left(c b+z_{1}\right) c^{-1} b^{-1}\left(p-\bar{p}_{1}\right)\right)=i-i^{*}
$$

even if in the rest of the model the relevant $y_{n}$ is $y_{n 2}$, this is due to the fact that investors anticipate that the bursting of the bubble will bring back the system to the steady-state prevailing before its beginning. The "convoluted", intermediate system would then be connected to the second system in a way analogous to that followed to connect the second system to the first. 
Finally, a sonewhat paradoxical situation is shown in Fig. 5. We see that, In this case, point 1 (the point to which the exchange rate would collapse werc it to collapse to the saddle path $s_{\text {, }}$ is on the right of the boundary Ifne $v=v_{2}$ so that in fact the long run equilibriun does not shift back to 1 making the saddle path S. relevant again. While point $y$ ito which the exchange rate would collapse to reach the sadile path $\left.S_{2}\right)$ is on the left of the $v=v$ 3 ne. which means that here the collapse of the bubbie would be enough to move the economy back to equilibrlum 1. 1.e. S, is not relevant. Unfortunately the predicament, cannot be avoided simply by ruling out bubbles producing such an outcome on grounds of rationality. In fact it is easy to show that an analogous deadlock may be the result of a monetary shock. In Fig. 6, we have at point 1 the long run equilibrium when $\mathrm{m}=$ mo and $y=y_{n i}$ at point 2 the long run equilibrlum when $m=m_{1}\left(\right.$ with $\left.m_{1}<m_{0}\right)$ and $y_{n}=y_{n 1}$ and at point 3 the long run equilibrium when $m=19$, and $y_{n}=y_{n 2}$, which is the value $y$ attains when the bound line $v=\underline{v}_{1}$ is crossed. Here again we have that, after the money decrease, $A$, the equilibrium point on the saddle path $S_{2}$, is on the right of $v=\underline{v}_{1}$, so that the saddle path to which it belongs is not relevant while B, the relevant point on the sadile path $S_{3}$. is on the left of $v=\underline{v}_{1}$, so that in fact at $B S_{2}$, not $S_{3}$, is the relevant sadile path.

Suming up, the treatment in this section has shown that a rational bubble in the foreign exchange market is quite capable of creating lasting damage to economic performance by reducing potential output in the presence of sunk-cost hysteresis. Thereduction in capital accumulation will also raise the natural rate of 
unemployment, unless movements in relative factor price lead to the adoption of more labour intensive techniques. ${ }^{11}$

We have also demonstrated that the long-run equilibrium nominal and real exchange rate are path-dependent, so that purchasing power parity need not hold, even in the long run, and that its violation in the long run, may be due to a temporary nominal shock. The theory of PPP has recently received a great deal of attention yet remains controversial. Most studies recognize the failure of PPP in the short run (this is in fact the point of departure of the Dornbusch model, which emphasizes the different speed of adjustment of asset markets and good markets). There is some empirical support for its failure in the long run as well: Frenkel (1981), Edison (1987), Corbae and Ouliaris (1988) among others, have suggested that divergences of exchange rates from PPP have been persistent. From the perspective of policy, we notice that to avoid hysteresis fixed exchange rates are not needed and that a regime in which real exchange rates are not allowed to get too far out of line, as with target zones, would suffice. ${ }^{12}$ To analyze properly the welfare effects of a bubble and derive the optimal policy prescriptions, we would require a completely specified growth level, which would mean, given the state of the art, making assumptions (e.g. perfectly flexible prices) which contradict those from which the Dornbusch model derives its interesting dynamic properties. However this is a tempting avenue for further research. 


\section{Smooth Adjustment in Capacity}

In this section we consider an alternative formulation of hysteresis in the natural level of income to which changes continuosly in proportion to its own difference from the actual level of income:

$$
D y_{n}=d\left(y-y_{n}\right)
$$

This can be viewed as a linear approximation to the differentiation of:

$$
y_{n}(s)=f \int_{-\infty}^{t}\left(y(s)-y_{n}(s)\right) d s
$$

which implies that the natural level of income is assumed to be a moving average of past actual income levels with geometrically declining weights. ${ }^{13}$ In fact, (20) is the continuous time analogue of a simple first-order partial adjustment mechanism:

$$
y_{t n}=a y_{t-1}+(1-a) y_{t-1}
$$

from which it can be obtained by proceeding to the limit as the time period goes to zero.

Substituting (1) and (2) in (20) and (4), we get to: 


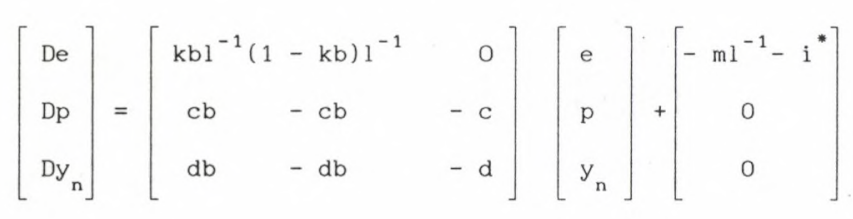

It is immediately evident that the transition matrix is singular, which is the condition for the model to exhibit hysteresis in the sense of having the stationary equilibrium depending on initial conditions.

Giavazzi and Wyplosz (1985) provide a formula to allow direct computation of the stationary equilibrium in linear dynamic systems with singular transition matrices. Instead of using this formula we adopt a short cut by noting that:

$$
D y_{n}=d c^{-1} D p
$$

Integrating from 0 to $t$ we get to:

$$
y_{n}=d c^{-1} p+y_{n}(0)-d c^{-1} p(0)
$$

so that the system can be reduced to two dimensions, by substituting (25) in (24):

$$
\left[\begin{array}{c}
\mathrm{De} \\
\mathrm{Dp}
\end{array}\right]=\left[\begin{array}{cc}
\mathrm{kbl}^{-1} & (1-\mathrm{kb}) \mathrm{l}^{-1} \\
\mathrm{cb} & -(\mathrm{cb}+\mathrm{d})
\end{array}\right]\left[\begin{array}{l}
\mathrm{p} \\
\mathrm{p}
\end{array}\right]+\left[\begin{array}{c}
-\mathrm{ml}^{-1}-\mathrm{i}^{*} \\
\mathrm{cy}(0)+\mathrm{dp}(0)
\end{array}\right]
$$


The determinant is again negative. In the stationary state we have:

$$
\begin{aligned}
& \bar{p}=\left(c\left(m+1 i^{*}\right)+k\left(d p(0)-c y_{n}(0)\right)\right)(d k+c)^{-1} \\
& \bar{y}=\bar{y}_{n}=\left(d\left(m+1 i^{*}\right)-\left(d p(0)-c y_{n}(0)\right)\right)(d k+c)^{-1} \\
& \bar{e}=\left(\left(c+d b^{-1}\right)\left(m+1 i^{*}\right)-(1-k b) b^{-1}\left(d p(0)-c y_{n}(0)\right)\right)(d k+c)^{-1}
\end{aligned}
$$

It is clear that the steady-state level of income and of the real exchange rate depends on nominal as well as real exogenous variables. Along the saddle path we have:

$$
e-\bar{e}=\left(c b+d+z_{1}\right) c^{-1} b^{-1}(p-\bar{p})
$$

where $z_{1}$ is the negative eigenvalue. To model a stochastic bubble the arbitrage equation has to be modified becoming :

$$
D e-n\left(e-\bar{e}-\left(c b+d+z_{1}\right) c^{-1} b^{-1}(p-\bar{p})\right)=i-\dot{i}^{*}
$$

When we calculate the long run values of the system after the crash we need the initial conditions for $p$ and $y_{n}$, i.e. the values of $p$ and $y_{n}$ when the bubble bursts. However, the difference $d p(t)-c y_{n}(t)$, which we use in the formulae for long run values is equal to dp(o) $c y_{n}(0)$, i.e. is a constant, which does not change as time passes. This means that the stationary equilibrium of the system with bubble and that of the system without bubble are the same. We then have: 


$$
[D e]=\left[\begin{array}{c}
n+k b l^{-1}-n c^{-1} b^{-1}(c b+d+z)+(1-k b) 1^{-1} \\
c b
\end{array}\right]\left[\begin{array}{c}
e-e^{-1} \\
p
\end{array}\right]
$$

This, again, has a saddie point equilibrium. Since the positive root is different from the one in the bubbleless system, all unstable trajectories are changed by bubbles. So we have that an exchange rate bubble has an impact on the dynamics of the economy, leading to changes not only in prices, interest rate and income but also in the non inflationary level of income. This may be specially important for the conduct of policy. interest rate and income but also in the non inflationary level of the latter. This may be specially important for the conduct of policy. If the authorities believe that the non inflationary level of income is a "natural" feature of the economy. which cannot be influenced by stabilization measures, they may not recognize a bubble, for instance a deflationary one, and so fail to fight it, e.g. by expanding money supply. ${ }^{14}$ imputing the change in the real exchange rate to an exogenous hange in the natural level of income and the simultaneous increase in prices to a change in core inflation. However the effects of a bubble are limited to the short run, in spite of the hysteretic character of the economy, so that after the explosion of the bubble the long-run values prevalling before its inception are regained. 


\section{Concluding Remarks.}

This paper offers another argument to the widespread uneasiness with the functioning of floating exchange rates by showing how large misalignments, which cannot be ruled out on grounds of rationality, may lead to scrappage of sunk-assets: potential output is thereby reduced. On the contrary standard models of exchange rate determination assume that exchange rate swings can have only temporary effects. We have also shown that not all forms of path-dependence in the non inflationary level of income lead to such persistent effects, which will present only if adjustment in capacity is discontinuous at the aggregate level. From the perspective of the literature on PPP, we have shown that if the aggregate investment functio is non linear with respect to the profit rate, large temporary shocks permanently the real exchange rate.

In this paper we have presented two simple models designed to demonstrate the potential of the argument rather than offer a complete analysis of the issues addressed. A natural way to extend the analysis conducted here would be to model explicitly

the investment decisions of firms, assuming rational expectations on their part, i. e. assuming they know the macro-process determining the exchange rate. This would require making assumptions concerning the market structure in which firms operate, their production functions etc. Also further theoretical and empirical research should be carried out to deal with the aggregation problem. Yet, the fact that hysteresis has been shown to arise for all degrees of persistence in the real exchange rates both in competitive and 
monopolistic situations means that the results we have achieved here as regards the macroeconomic implications of sunk-cost hysteresis should be robust with respect to such extensions. 
Notes

1. A wide-ranging survey is provided in chapter 5 of Blanchard and Fisher (1989).

2. The relevant literature for exchange rate bubbles is that on hyperinflation and hyperdeflations, since any bubble in the exchange rate would have to be reflected either in a bubble in the price level at home or abroad or in a divergent deviation from PPP, which is impossible since agents cannot expect unexploited potential profits from commodity arbitrage to grow without 1 imits.

In an infinite horizon setting it is possible to rule out hyperdeflations - not hyperinflations - because of a necessary trasversality condition.

Obstfeld and Rogoff (1983) show that if the goverment with some probability fractionally backs the currency by guaranteeing a minimal redemption value speculative hyperinflations are ruled out.

Starting from the impossibility of hyperdeflations, Diba and Grossman (1988) show that rational inflationary bubbles can exist only if they have been present since the introduction of the flat money. However if the bubble is stochastic, the probability that an hyperdeflation leads to violation of the transversality condiction is very small; since there is evidence that individuals systematically ignore very small probability events, this considerably weakens the arguments against hyperdef lations.

3. They assume capital flows are exogenous so that the exchange rate will take whatever value is necessary to move the balance of trade to the level where it exactly offsets the capital flows. Now, the trading volume in foreign exchange markets is many $t$ imes greater than the volume of international trade in goods and services. This fact strongly supports the view that exchange rates adjust to equilibrate the international demand for stocks of national assets as opposed to adjusting to equilibrate the international demand for flows of national goods, notwithstanding the poor empirical performance of "asset market" models of exchange rate determination (see Dornbusch and Frankel 1987).

4. The fact that we have chosen to study a rational bubble does not mean that we do not belleve in "irrationality" as a source of noise in assets markets. What is interesting in the rational bubbles literature is that "rationality" is not always enough to ensure market stability. Indeed a very natural "sequel" to this paper would be to consider the impact on the economic structure of other kinds of departures from the paradigm of efficiency on the foreign exchange market, moving the focus of 
analysis from "growing bubbles" to "fads" and "information bubbles", to adopt the taxonomy proposed by Camerer (1989).

5. It is easy to show, using the analytical frameworkof sunk-cost hysteresis models that hysteresis can also arise from "learning by doing" by producers or "habit formation" by consumers.

6. The spectrum of the different structures considered goes form Baldwin and Krugman (1986), who analyse the case of a monopolistic firm, to Dixit (1987) who assumes perfect competition.

7. He builds a simple counter example showing that the effect is absent for i.i.d. expectations, if the profit function is linear in the real exchange rate.

8. Notice that while hysteresis models focus mainly on the fixed-scale project case, i.e. on entry and exit decisions, they can be easily extended to cover the incremental investment cases. Again we obtain that capacity is adjusted only when the forcing variable crosses the limits of the hysteresis band for that level of capacity.

9. Sunk-cost hysteresis models investigate the case in which it is not possible for firms to keep their capacity without incurring in maintenance costs and/or operating above a minimum level. Otherwise an investment would never be abandoned, since it could be kept alive at an infinitesimal loss by choosing a very low level of production. This is the fundamental difference between hysteresis models an irreversible investment models where scrapping is never profitable (see, for instance Pindyck 1988 ).

10. As we said before, the values of the triggers will depend on the expectations of the firms as regards the process governing the real exchange rate. An easy way to obtain a qualitative picture for the case in which the exchange rate is driven by a bubble is to assume that firms only know the current and the long run value of the real exchange rate as well as the probability $n$ of the bubble bursting and solve their maximization problem by assuming that, after the inception of the bubble, over the short time interval $d t$ the real exchange rate will jump to the long run equilibrium level with probability ndt, otherwise it will remain unchanged to the current level. Thiskind of Poisson process is shown by Dixit (1987) to generate for each firm an inaction band.

11. In fact, as is well known other mechanisms for generating hysteresis in the natural rate of unemployment have been analysed arising from the functioning of the labour market itself: insiders' power, outsiders'loss of human capital and/or use by firms of past hystory of unemployment as a screening device etc. Moreover there are unrecoverable costs related to labour( hiring, training and firing costs), so that sunk-cost hysteresis may arise in labour demand as well as in capital 
investment. See in a wide literature the articles in Cross (1988).

12. It is not possible here to discuss the weak points of target zones as a halfway solution between fixed and floating rates. Quoting from the Robbins Lectures 1988 by P. Krugman: "target zones will present both the problem of a temptation to try to sustain the wrong exchange rate, and the risk of speculative attack on the target that an unsustainable zone presents."

13. This is the formulation for hysteresis in the NAIRU, which invoking Okuns' law means also hysteresis in the "natural "level of income, firstly proposed by Hargreaves-Heap (1980).

14. As is well known, with perfect substitutability between domestic and foreign assets, sterilized intervention on the foreign exchange market is ineffective but as signal of policy makers intentions. 


\section{References}

Baldwin, R. (1989) "Sunk-cost Hysteresis," NBER Working Paper \# 2911. ---- and P. Krugman (1986) "Persistent Trade Effects of Large Exchange Rate Shocks, "NBER Working Paper \# 2017.

---- and R. Lyons (1989) "Exchange Rates Hysteresis: the Real Effects of Large versus Small Policy Misalignments, "NBER Working Paper \# 2828.

Bean, C. (1990) "Capital Shortages and Persistent Unemployment," Economic Policy, 13-53.

Blanchard, O. (1979) "Speculative Bubbles, Crashes and Rational Expectations," Economic Letters 3, 387-389.

Blanchard, O. and S. Fischer (1989) Lectures on Macroeconomics. Cambridge: MIT Press.

Blanchard O, and M. Watson (1982) "Bubbles, Rational Expectations and Financial Markets" in $P$ Wachtel (ed.), Crises in the Economic and Financial Structure. Lexington: D. C. Heath and Co.

Camerer, C. (1989) "Bubbles and Fads in Asset Prices," Journal of Economic Surveys 3(1), 13-41.

Corbae, D. and S. Ouliaris (1988) "Cointegration and Tests of Purchasing Power Parity," Review of Economics and Statistics, 508-511.

Cross, R. (1988) (ed.), Unemployment, Hysteresis \& the Natural Rate Hypothesis. Oxford and New York: Basil Blackwell.

Diba, B. and H. Grossman (1988) "Rational inflationary bubbles," Journal of Monetary Economics 21, 35-46. 
Dixit, A. (1987) "Entry and Exit Decisions of Firms under Fluctuating Real Exchange Rates," Mimeo, Princeton University.

---- (1988) "Hysteresis, Import Penetration and Exchange Rate Pass-through," Quarterly Journal of Economics CIV, 205-228.

---- (1989) "Entry and Exit Decisions under Uncertainty," Journal of Political Economy 97, 620-638.

Dornbusch, R.(1976) "Expectations and exchange rate dynamics," Journal of Political Economy 84, 1161-1176.

---- (1982) "Equilibrium and Disequilibrium Exchange Rates," Mimeo, M. I.T.

Dornbusch, R. and J. Frankel (1987) "The Flexible Exchange Rate System: Experience and Alternatives," NBER Working Paper \# 2464. Edison H. G. (1987) "Purchasing Power Parity in the Long-run : a Test of the Dollar/Pound Exchange Rate (1890-1978)," Journal of Money, Credit and Banking, 376-387.

Frenkel, J. A. (1981) "The Collapse of PPP during the 1970s," European Economic Review 16, 145-165.

Giavazzi, F. and C. Wyplosz (1985) "The Zero Root Problem: a Note on

the Dynamic Determination of the Stationary Equilibrium in Linear Models," Review of Economic Studies 52, 353-357.

Hargreaves-Heap, S.P. (1980) " Choosing the Wrong Natural Rate, Accelerating Inflation or Decelerating Unemployment and Growth," Economic Journal 90, 611-20.

Klemperer, P.D. (1987) "Entry Deterrence in Markets with Consumers Switching Costs," Economic Journal Supplement 97, 99-117.

Krugman, P. (1988) Exchange rate instability, Robbins Lectures at L. S. E., Cambridge: MIT Press. 
Miller, M. and P. Weller (1990) "Currency Bubbles which Affect Fundamentals: a Qualitative Treatment," The Economic Journal $100,170-179$

Obstfeld, M.and K. Rogoff (1983) "Speculative Hyperinflations in Maximizing Models: Can We Rule Them out?," Journal of Political Economy 91, 675-687.

Pindyck, R. (1988) "Irreversible Investment, Capital Choice and the Value of the Firm," American Economic Review, 969-985.

Schmalensee, R. (1982) "Product Differentiation Advantages of Pioneering Brands," American economic Review 72, 349-365.

Wilson, C. A. (1979) "Anticipated Shocks and Exchange Rate Dynamics," Journal of Political Economy June. 
Mark, N. C. (1990) "Real and Nominal Exchange Rates in the Long-run: an Empirical Investigation," Journal of International Economics 28, 115-136. 


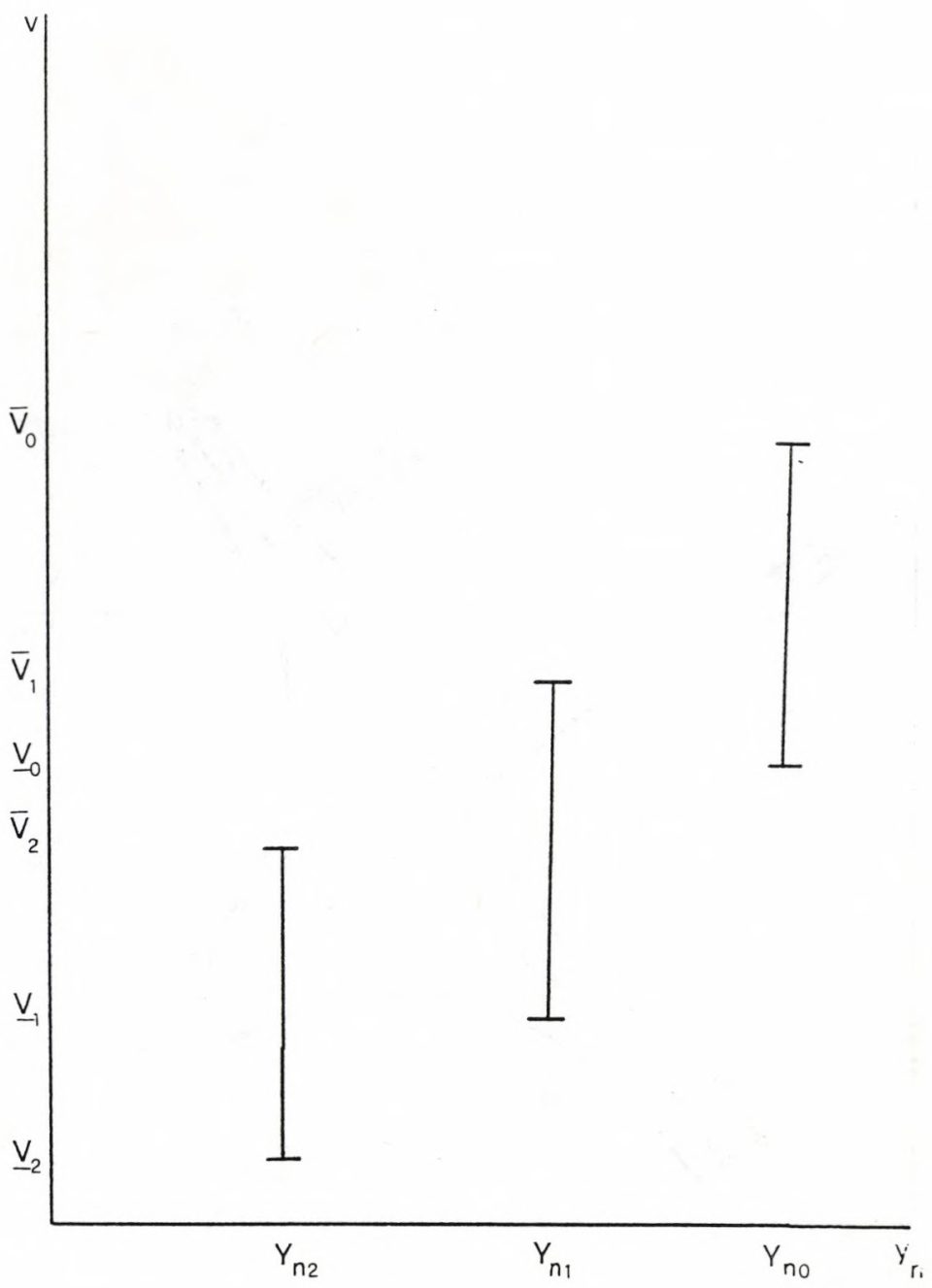

F $\mid \mathrm{G} . \quad 1$ 


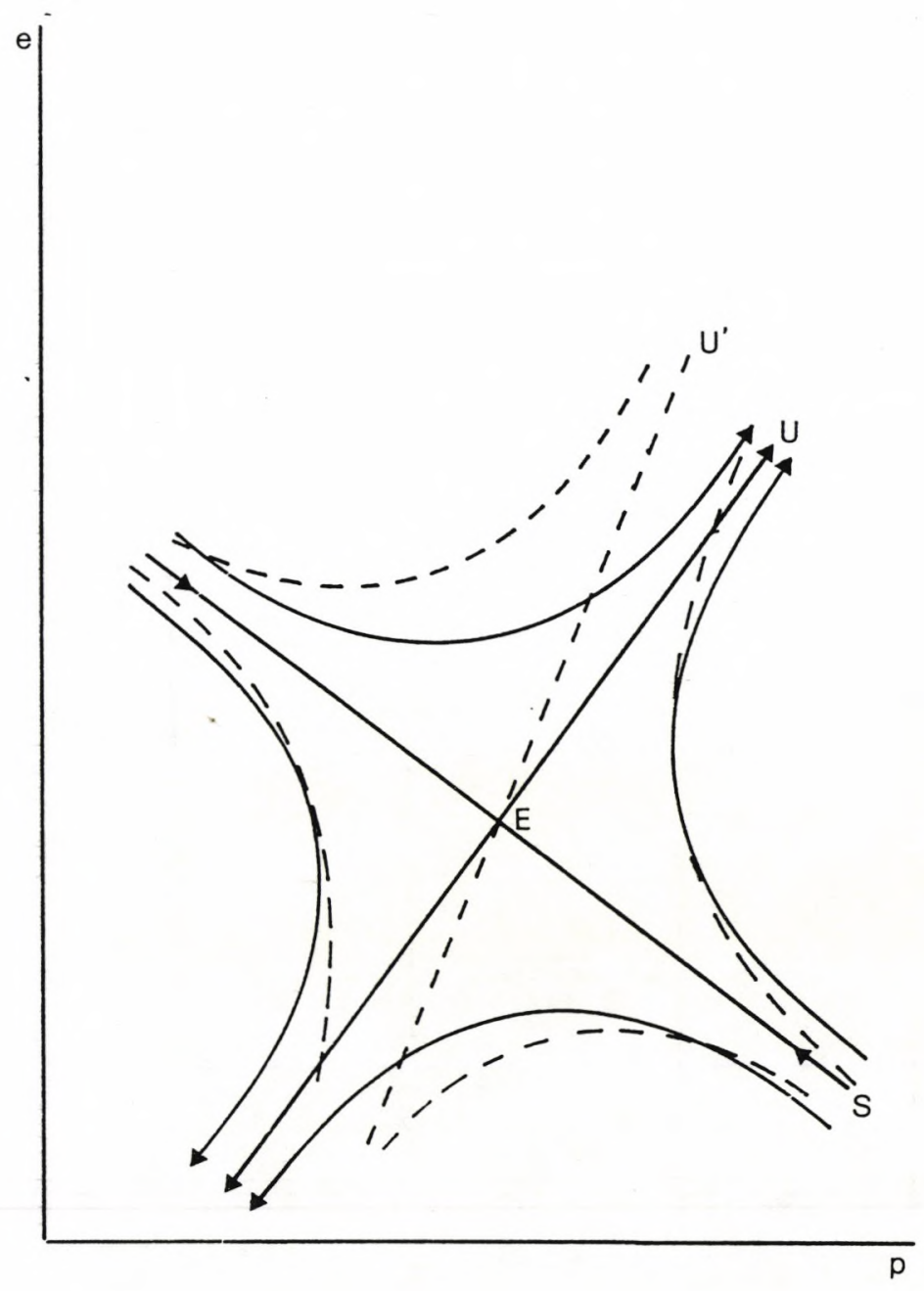

F.IG. 2 


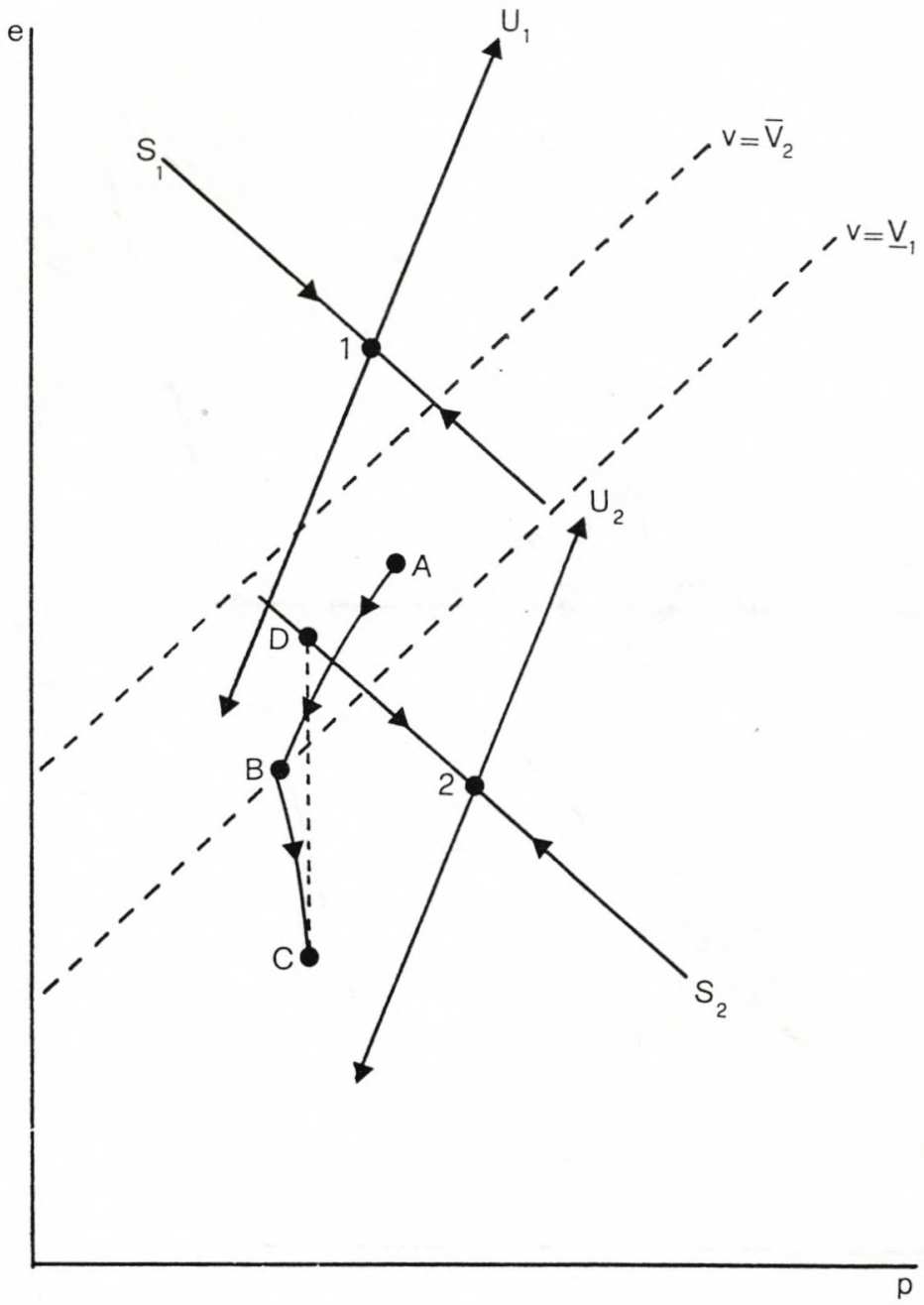

FIG. 3 


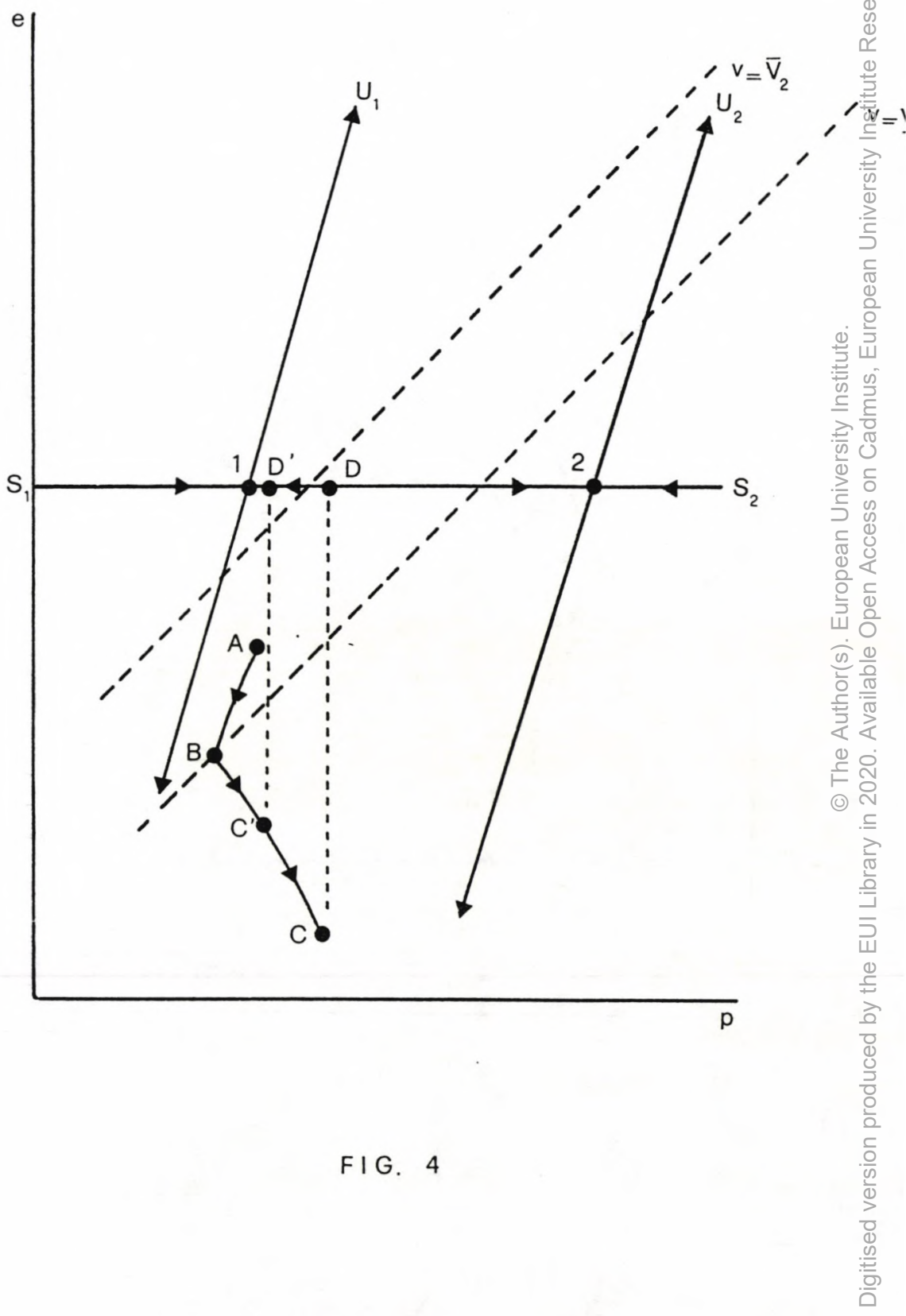




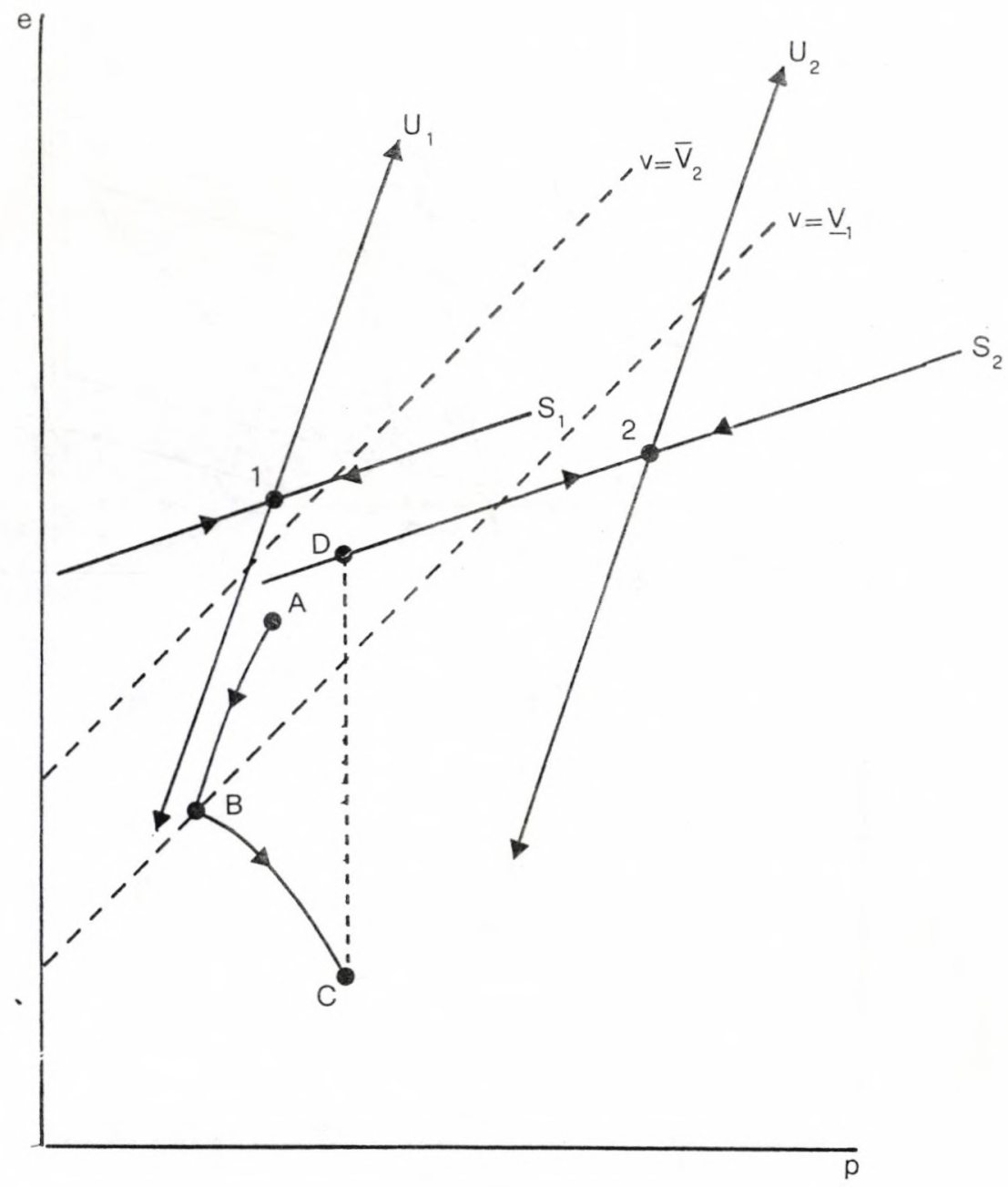

FIG. 5 


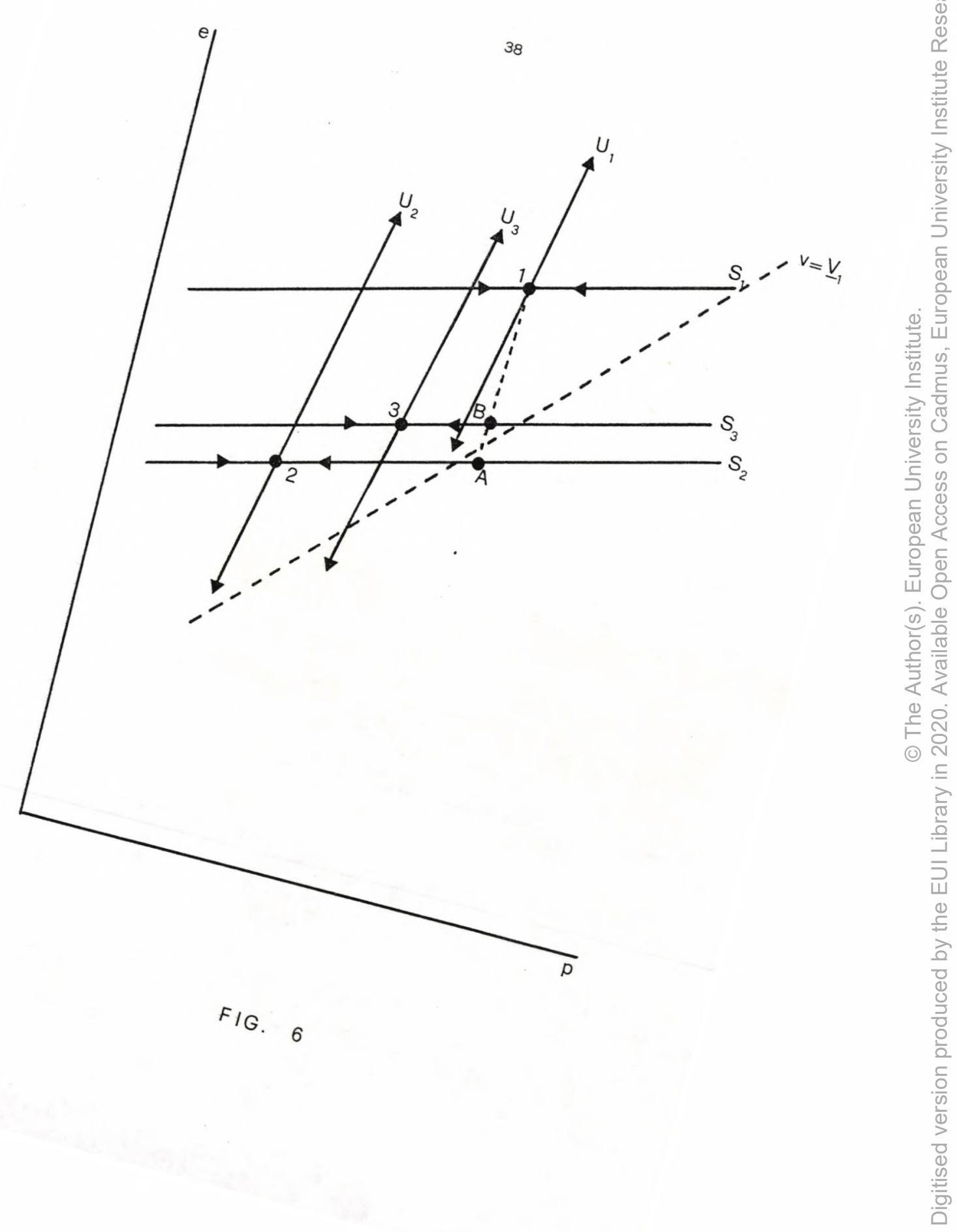




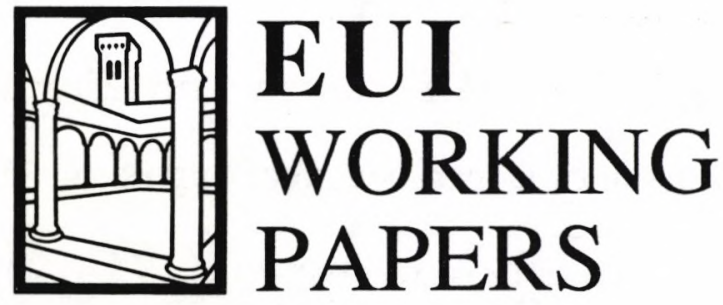

EUI Working Papers are published and distributed by the European University Institute, Florence

Copies can be obtained free of charge - depending on the availability of stocks - from:

The Publications Officer

European University Institute

Badia Fiesolana

I-50016 San Domenico di Fiesole (FI)

Italy

Please use order form overleaf 


\title{
團 \\ Publications of the European University Institute \\ Economics Department Working Paper Series
}

To

\author{
Economics Department WP \\ European University Institute \\ Badia Fiesolana \\ I-50016 San Domenico di Fiesole (FI) \\ Italy
}

From Name

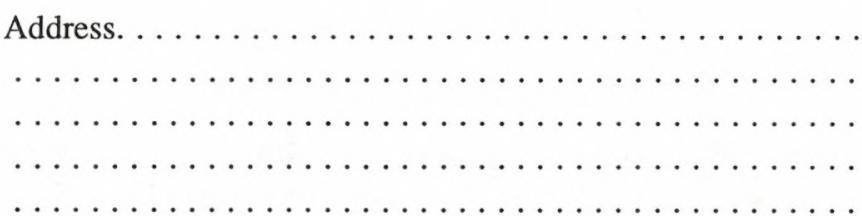

(Please print)

$\square$ Please enter/confirm my name on EUI Economics Dept. Mailing List

$\square$ Please send me a complete list of EUI Working Papers

$\square$ Please send me a complete list of EUI book publications

$\square$ Please send me the EUI brochure Academic Year 1992/93

Please send me the following EUI ECO Working Paper(s):

No, Author

Title:

No, Author

Title:

No, Author

Title:

No, Author

Title:

Date $\ldots \ldots \ldots \ldots$ Signature 


\section{Working Papers of the Department of Economics Published since 1990}

ECO No. 90/1

Tamer BASAR and Mark SALMON Credibility and the Value of Information Transmission in a Model of Monetary Policy and Inflation

ECO No. 90/2

Horst UNGERER

The EMS - The First Ten Years

Policies - Developments - Evolution

ECO No. 90/3

Peter J. HAMMOND

Interpersonal Comparisons of Utility:

Why and how they are and should be made

ECO No. 90/4

Peter J. HAMMOND

A Revelation Principle for (Boundedly) Bayesian Rationalizable Strategies

ECO No. 90/5

Peter J. HAMMOND

Independence of Irrelevant Interpersonal Comparisons

ECO No. 90/6

Hal R. VARIAN

A Solution to the Problem of Externalities and Public Goods when Agents are Well-Informed

ECO No. 90/7

Hal R. VARIAN

Sequential Provision of Public Goods

ECO No. 90/8

T. BRIANZA, L. PHLIPS and J.F. RICHARD

Futures Markets, Speculation and Monopoly Pricing

ECO No. 90/9

Anthony B. ATKINSON/ John

MICKLEWRIGHT

Unemployment Compensation and

Labour Market Transition: A Critical

Review

ECO No. 90/10

Peter J. HAMMOND

The Role of Information in Economics
ECO No. 90/11

Nicos M. CHRISTODOULAKIS

Debt Dynamics in a Small Open

Economy

ECO No. 90/12

Stephen C. SMITH

On the Economic Rationale for

Codetermination Law

ECO No. 90/13

Elettra AGLIARDI

Learning by Doing and Market Structures

ECO No. 90/14

Peter J. HAMMOND

Intertemporal Objectives

ECO No. 90/15

Andrew EVANS/Stephen MARTIN

Socially Acceptable Distortion of

Competition: EC Policy on State Aid

ECO No. 90/16

Stephen MARTIN

Fringe Size and Cartel Stability

ECO No. $90 / 17$

John MICKLEWRIGHT

Why Do Less Than a Quarter of the Unemployed in Britain Receive

Unemployment Insurance?

ECO No. 90/18

Mrudula A. PATEL

Optimal Life Cycle Saving With

Borrowing Constraints:

A Graphical Solution

ECO No. 90/19

Peter J. HAMMOND

Money Metric Measures of Individual and Social Welfare Allowing for Environmental Externalities

ECO No. 90/20

Louis PHLIPS/

Ronald M. HARSTAD

Oligopolistic Manipulation of Spot

Markets and the Timing of Futures

Market Speculation 
ECO No. 90/21

Christian DUSTMANN

Earnings Adjustment of Temporary

Migrants

ECO No. 90/22

John MICKLEWRIGHT

The Reform of Unemployment

Compensation:

Choices for East and West

ECO No. 90/23

Joerg MAYER

U. S. Dollar and Deutschmark as

Reserve Assets

ECO No. 90/24

Sheila MARNIE

Labour Market Reform in the USSR:

Fact or Fiction?

ECO No. 90/25

Peter JENSEN/

Niels WESTERGÅRD-NIELSEN

Temporary Layoffs and the Duration of

Unemployment: An Empirical Analysis

ECO No. 90/26

Stephan L. KALB

Market-Led Approaches to European

Monetary Union in the Light of a Legal

Restrictions Theory of Money

ECO No. 90/27

Robert J. WALDMANN

Implausible Results or Implausible Data?

Anomalies in the Construction of Value

Added Data and Implications for Esti-

mates of Price-Cost Markups

ECO No. 90/28

Stephen MARTIN

Periodic Model Changes in Oligopoly

ECO No. 90/29

Nicos CHRISTODOULAKIS/

Martin WEALE

Imperfect Competition in an Open

Economy
* * *

ECO No. 91/30

Steve ALPERN/Dennis J. SNOWER Unemployment Through 'Learning From Experience'

ECO No. 91/31

David M. PRESCOTT/Thanasis STENGOS

Testing for Forecastible Nonlinear

Dependence in Weekly Gold Rates of Return

ECO No. 91/32

Peter J. HAMMOND

Harsanyi's Utilitarian Theorem:

A Simpler Proof and Some Ethical

Connotations

ECO No. 91/33

Anthony B. ATKINSON/

John MICKLEWRIGHT

Economic Transformation in Eastern

Europe and the Distribution of Income

ECO No. 91/34

Svend ALBAEK

On Nash and Stackelberg Equilibria

when Costs are Private Information

ECO No. 91/35

Stephen MARTIN

Private and Social Incentives

to Form R \& D Joint Ventures

ECO No. 91/36

Louis PHLIPS

Manipulation of Crude Oil Futures

ECO No. 91/37

Xavier CALSAMIGLIA/Alan KIRMAN

A Unique Informationally Efficient and

Decentralized Mechanism With Fair

Outcomes

ECO No. 91/38

George S. ALOGOSKOUFIS/

Thanasis STENGOS

Testing for Nonlinear Dynamics in

Historical Unemployment Series

ECO No. 91/39

Peter J. HAMMOND

The Moral Status of Profits and Other

Rewards:

A Perspective From Modern Welfare Economics 
ECO No. 91/40

Vincent BROUSSEAU/Alan KIRMAN

The Dynamics of Learning in Mis-

Specified Models

ECO No. 91/41

Robert James WALDMANN

Assessing the Relative Sizes of Industryand Nation Specific Shocks to Output

ECO No. 91/42

Thorsten HENS/Alan KIRMAN/Louis PHLIPS

Exchange Rates and Oligopoly

ECO No. $91 / 43$

Peter J. HAMMOND

Consequentialist Decision Theory and

Utilitarian Ethics

ECO No. 91/44

Stephen MARTIN

Endogenous Firm Efficiency in a Cournot Principal-Agent Model

ECO No. $91 / 45$

Svend ALBAEK

Upstream or Downstream Information Sharing?

ECO No. $91 / 46$

Thomas H. McCURDY/

Thanasis STENGOS

A Comparison of Risk-Premium

Forecasts Implied by Parametric Versus

Nonparametric Conditional Mean

Estimators

ECO No. 91/47

Christian DUSTMANN

Temporary Migration and the Investment into Human Capital

ECO No. $91 / 48$

Jean-Daniel GUIGOU

Should Bankruptcy Proceedings be

Initiated by a Mixed

Creditor/Shareholder?

ECO No. 91/49

Nick VRIEND

Market-Making and Decentralized Trade

ECO No. 91/50

Jeffrey L. COLES/Peter J. HAMMOND

Walrasian Equilibrium without Survival:

Existence, Efficiency, and Remedial

Policy
ECO No. 91/51

Frank CRITCHLEY/Paul MARRIOTT/ Mark SALMON

Preferred Point Geometry and Statistical Manifolds

ECO No. 91/52

Costanza TORRICELLI

The Influence of Futures on Spot Price Volatility in a Model for a Storable

Commodity

ECO No. 91/53

Frank CRITCHLEY/Paul MARRIOTT/ Mark SALMON

Preferred Point Geometry and the Local Differential Geometry of the Kullback-

Leibler Divergence

ECO No. 91/54

Peter MØLLGAARD/

Louis PHLIPS

Oil Futures and Strategic

Stocks at Sea

ECO No. 91/55

Christian DUSTMANN/

John MICKLEWRIGHT

Benefits, Incentives and Uncertainty

ECO No. 91/56

John MICKLEWRIGHT/

Gianna GLANNELLI

Why do Women Married to Unemployed Men have Low Participation Rates?

ECO No. 91/57

John MICKLEWRIGHT

Income Support for the Unemployed in Hungary

ECO No. 91/58

Fabio CANOVA

Detrending and Business Cycle Facts

ECO No. 91/59

Fabio CANOVA/

Jane MARRINAN

Reconciling the Term Structure of

Interest Rates with the Consumption

Based ICAP Model

ECO No. 91/60

John FINGLETON

Inventory Holdings by a Monopolist Middleman 
ECO No. 92/61

Sara CONNOLLY/John

MICKLEWRIGHT/Stephen NICKELL

The Occupational Success of Young Men

Who Left School at Sixteen

ECO No. $92 / 62$

Pier Luigi SACCO

Noise Traders Permanence in Stock

Markets: A Tâtonnement Approach.

I: Informational Dynamics for the Two-

Dimensional Case

ECO No. $92 / 63$

Robert J. WALDMANN

Asymmetric Oligopolies

ECO No. 92/64

Robert J. WALDMANN/Stephen

C. SMITH

A Partial Solution to the Financial Risk and Perverse Response Problems of Labour-Managed Firms: Industry-

Average Performance Bonds

ECO No. 92/65

Agustín MARAVALL/Víctor GÓMEZ

Signal Extraction in ARIMA Time Series Program SEATS

ECO No. $92 / 66$

Luigi BRIGHI

A Note on the Demand Theory of the

Weak Axioms

ECO No. 92/67

Nikolaos GEORGANTZIS

The Effect of Mergers on Potential

Competition under Economies or

Diseconomies of Joint Production

ECO No. 92/68

Robert J. WALDMANN/

J. Bradford DE LONG

Interpreting Procyclical Productivity:

Evidence from a Cross-Nation Cross-

Industry Panel

ECO No. 92/69

Christian DUSTMANN/John

MICKLEWRIGHT

Means-Tested Unemployment Benefit

and Family Labour Supply: A Dynamic

Analysis
ECO No. $92 / 70$

Fabio CANOVA/Bruce E. HANSEN

Are Seasonal Patterns Constant Over

Time? A Test for Seasonal Stability

ECO No. 92/71

Alessandra PELLONI

Long-Run Consequences of Finite

Exchange Rate Bubbles 

